\title{
Nanotechnology as a Sustainable Approach for Achieving Sustainable Future
}

\author{
Nora Mohammed Rehan \\ Architecture Department, Faculty of Engineering, Ahram Canadian University, Cairo, Egypt \\ Email: nora.rehan@yahoo.com
}

How to cite this paper: Rehan, N.M. (2021) Nanotechnology as a Sustainable Approach for Achieving Sustainable $\mathrm{Fu}-$ ture. World Journal of Engineering and Technology, 9, 877-890.

https://doi.org/10.4236/wjet.2021.94060

Received: July 24, 2021

Accepted: November 16, 2021

Published: November 19, 2021

Copyright (c) 2021 by author(s) and Scientific Research Publishing Inc. This work is licensed under the Creative Commons Attribution International License (CC BY 4.0).

http://creativecommons.org/licenses/by/4.0/ (c) (i) Open Access

\begin{abstract}
The nanotechnology revolution affected positively Architecture. Using nanotechnology is considered one of the most successful modern methods to achieve sustainable buildings with high functional efficiency. The discipline is Nano architecture, which uses Nanomaterials, products, or even Nano-shapes in the treatment of structure and construction. Despite the economic and urban advantages of using nanotechnology in the field of architecture and urbanism, we note that using nanotechnology is limited to some buildings uses in the city centers until now such as Administrative, commercial, educational, health, and recreational buildings or residential buildings. In spite of that, we found that nanotechnology was not used in priority buildings as "nuclear power plants" as it is considered one of the most eligible buildings to rely on nanotechnology to achieve safety, security, and functional efficiency requirements which have a great impact on advancing the movement of urban development. From this standpoint, the research recommends the necessity of following a methodology to activate the establishment of nuclear power plants with such technology to preserve the safety of construction, reduce energy consumption, conserve economic resources and reduce pollution. The research is exposed to highlight a set of case studies that used such an effective technique and conclude a group of criteria that are recommended to be followed in the implementation and construction of the Dabaa plant in Egypt to achieve a sustainable nuclear power plant. So the research objective aims to adopt the idea of applying nanotechnology in various uses, whether it is in the city center or the outskirt of the city in order to develop these urban cities and transform them into smart sustainable environmental cities depending on nanotechnology aspects to achieve new sustainability scenario that accommodates the objectives of sustainability, with the support of new technologies. From this point of view, the research presents a proposal that includes a set of points that are recommended to be followed based on nanotechnology to achieve sustainability in the implementation of the Dabaa nuc-
\end{abstract}


lear power plant in Egypt; which will have a great impact in advancing the movement of urban development in Egypt through improving the envelope of an urban typology, using nanotechnology materials on the façades, roofs, and external renovations with suitable constructive systems and in an easier way.

\section{Keywords}

Nanotechnology, Sustainable City, Smart Building, Nuclear Power Plant

\section{Introduction}

This research is directed towards solving the problem on one hand the new technology prompting the architects to think in a new way for architecture, developments and formation, and on the other hand the emergence of new materials and applications, as well as the change in the style of structural systems for new sustainable buildings [1].

Nanotechnology identifies its characteristics, showing its enormous potential to create new materials and devices that will be useful in developing future cities, which will be inhabited by forthcoming generations of humanity [2]. In this paper, we review the main features that characterize nanotechnology.

\section{Nanotechnology}

"Nanotechnology" goes beyond Nano-science, and aims to convert the basic knowledge that it provides us with regarding the new properties of materials and goods, to improve existing products or propose radically new ones [3]. Thus it is

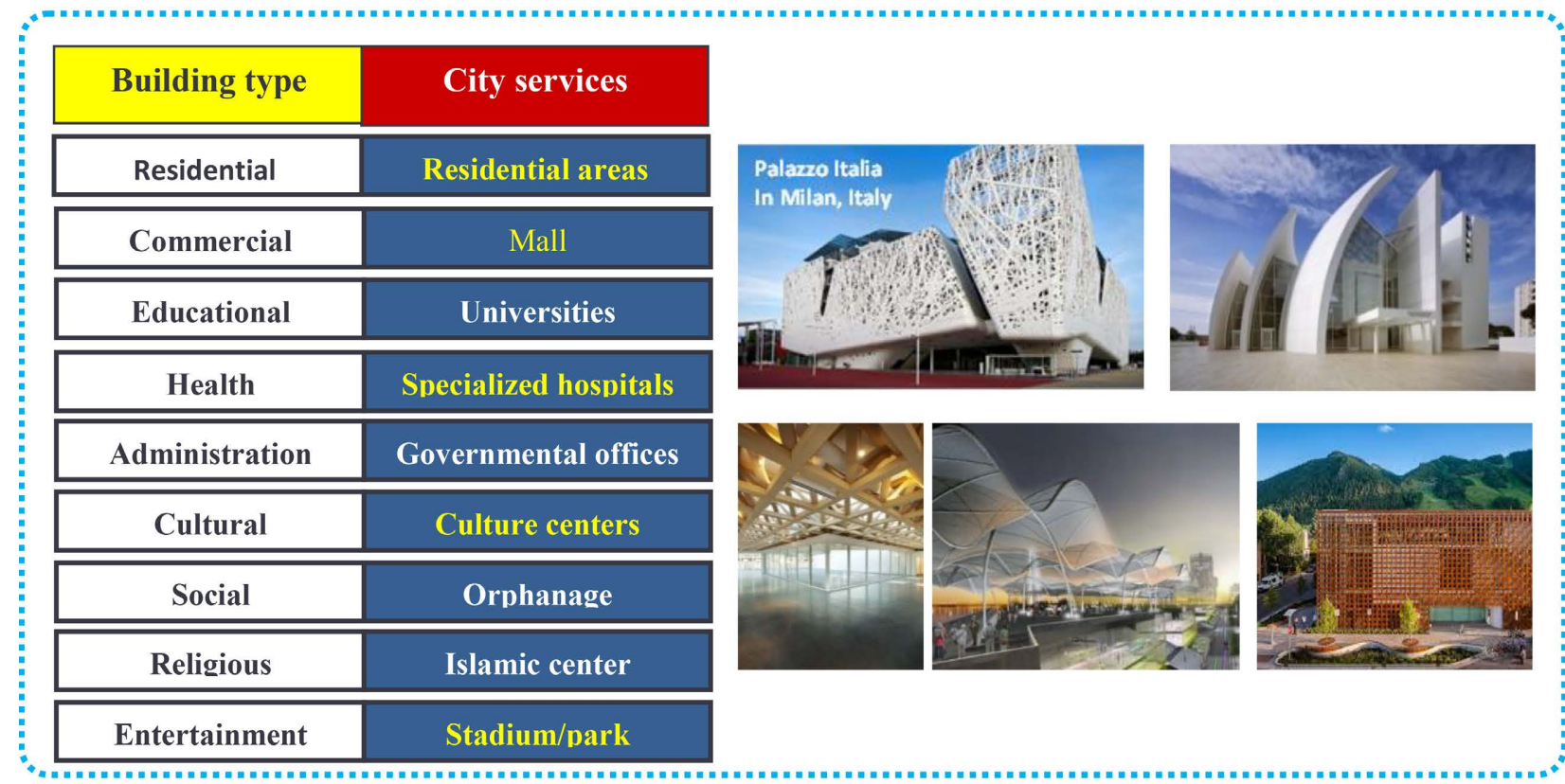

Figure 1. Some main services in city center that use nanotechnology. Source: The author. 
clear that nanotechnology is essentially concerned with the application of knowledge arising from Nano-science. Smart cities are slowly becoming a reality, developing pilot projects in many parts of the world (Amsterdam, Dubai, Helsinki, San Diego, San Francisco, Spain) by mid-century, many of our cities will have reached reasonable levels of "intelligence" [4]. Nanomaterials are not only useful for some partial requirements like roof and facades; they also expand some design possibilities both for sustainable design strategies and architects [5]. Nano construction materials are intelligent to achieve energy efficiencies and environmental comfort. We note using nanotechnology in different buildings in city center as shown in Figure 1.

The search will highlight aims of nanotechnology, its factors and case studies for such buildings in city center and the extent of the possibility of applying this technology in other buildings on the outskirts of the city.

\section{Aims of Technological Adaptability}

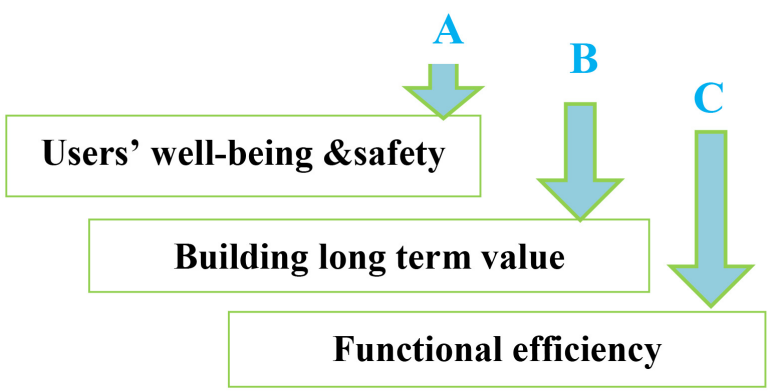

\section{A-Users' well-being and safety:}

- Comfort.

- Health.

- Safety.

- Indoor environmental quality.

- Life quality.

- Interactivity with the building and other users.

B-Building long term value [6]:

- Longevity and viability.

- Upgraded image.

- Modern components with low cost.

- Fit for different uses and users (residential, commercial, offices, cultural, etc.) to suit market demands.

- Cost effectiveness.

- Fit into and add to the environment by:

- Preserved connection with buildings' surroundings (other buildings, neighborhood);

- Harmless, yet Positive impact of the building on the environment;

- Energy efficiency.

C-Functional efficiency: 
- Flexibility, Multi-functional and trans-functional spaces [7].

- Efficient physical and virtual connections (Figure 2, Figure 3).

\section{Intelligent Building}

Provide an optimized solution of sustainability and intelligence that will help the agenda of living in a healthy, comfortable, and technologically advanced world. A building that uses both technology and process to create a facility that is safe, healthy and comfortable and enables productivity and well-being of its occupants. Smart or clever buildings, perhaps focus on control systems, but intelligent buildings go far beyond this [8]. An intelligent building has an implicit logic that effectively evolves with changing user requirements and technology, ensuring

\section{Aims of Technological Adaptability: \\ - Users' well-being and safety. \\ - Building long term value. \\ - Functional efficiency.}

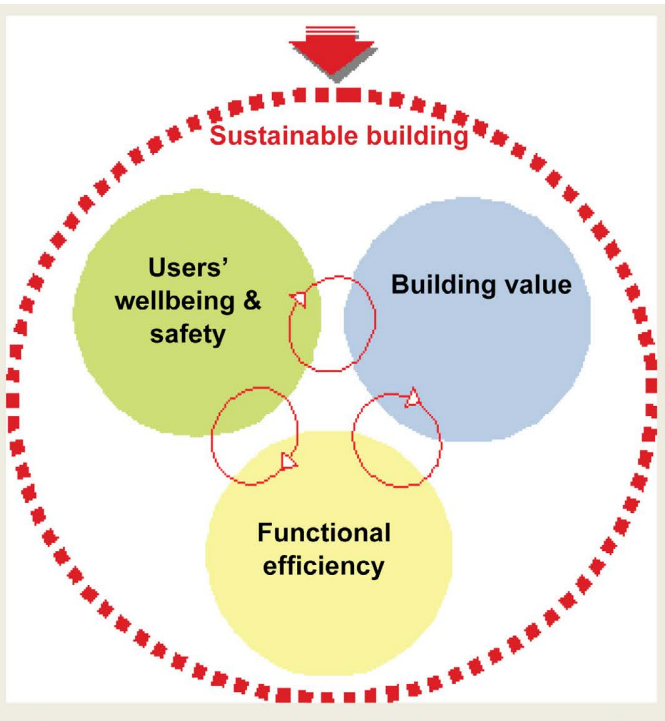

Figure 2. Aims of technological adaptability. Source: Faiza Nakib, technological adaptability, an approach towards a flexible and sustainable architecture, international conference on technology \& sustainability in the built environment, Riyadh, Saudi Arabia, Volume: 3, January 2010.

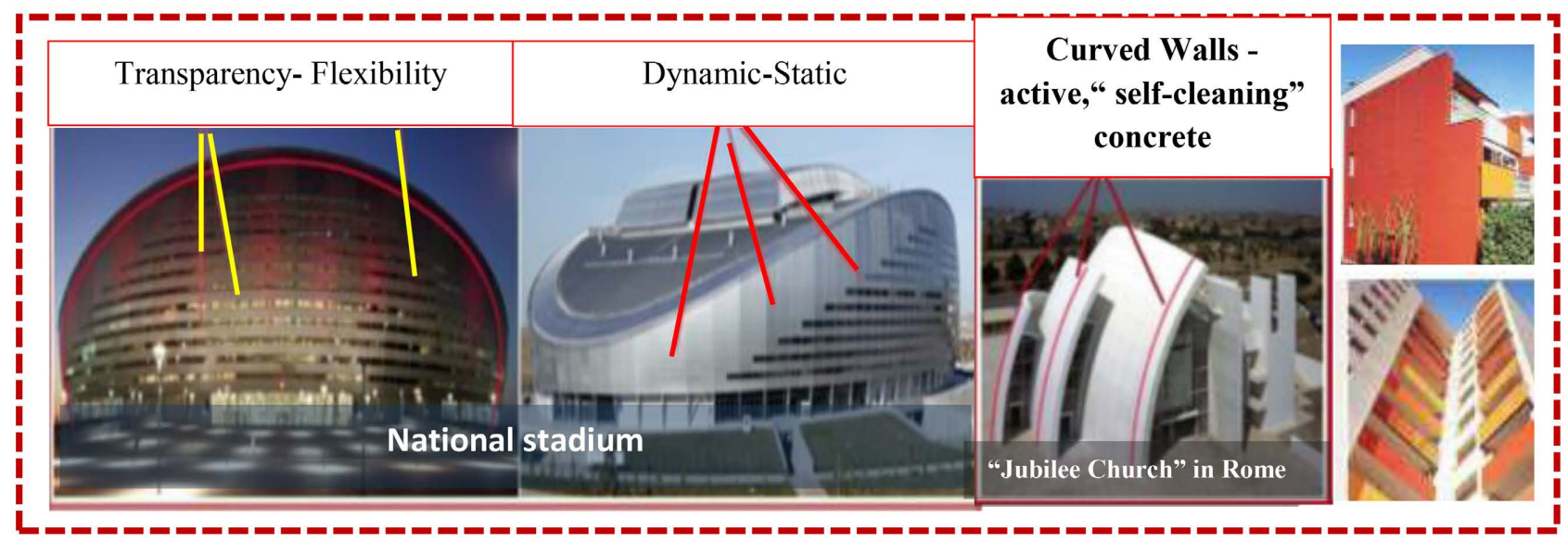

Figure 3. Intelligent building technologies effects on sustainability issues. Source: F. Pacheco-Torgala, Said Jalali, and nanotechnology: Advantages and drawbacks in the field of construction and building materials, Construction and Building Materials Volume 25, Issue 2, February 2011. 
continued and improved intelligent operation, maintenance and optimization [9]. It exhibits key attributes of environmental sustainability to benefit present and future generations. The design and construction of building envelopes involve the use of multiple layers of different materials to achieve a wide array of functionalities, including strength, light filtering, thermal insulations, sound insulations, weather resistance and architectural appearance.

\section{Factors Affecting Criteria of Intelligent Building}
A) CR-Construction Requirement.
B) EC-Environment Control.
C) WM-Water Management.
D) DW-Disposal Waste.
E) IBA-Integrating Building.

\section{Case Study 1: Residential Buildings}

The Nano-House is a new type of ultra-energy efficient house exploiting the new materials being developed by nanotechnology. Hydro-House uses natural airflow and seawater to cool and make the greenhouse humid. Seawater is evaporated at the facades of the greenhouse; as air passes into the green house, it increases the humidity [10]. But the smart part is in the structural columns, which also serves as supports for the growing racks [11]. When it rains, fresh rain water is allowed to trickle down from the roof, within the cylindrical columns (Figure 4).
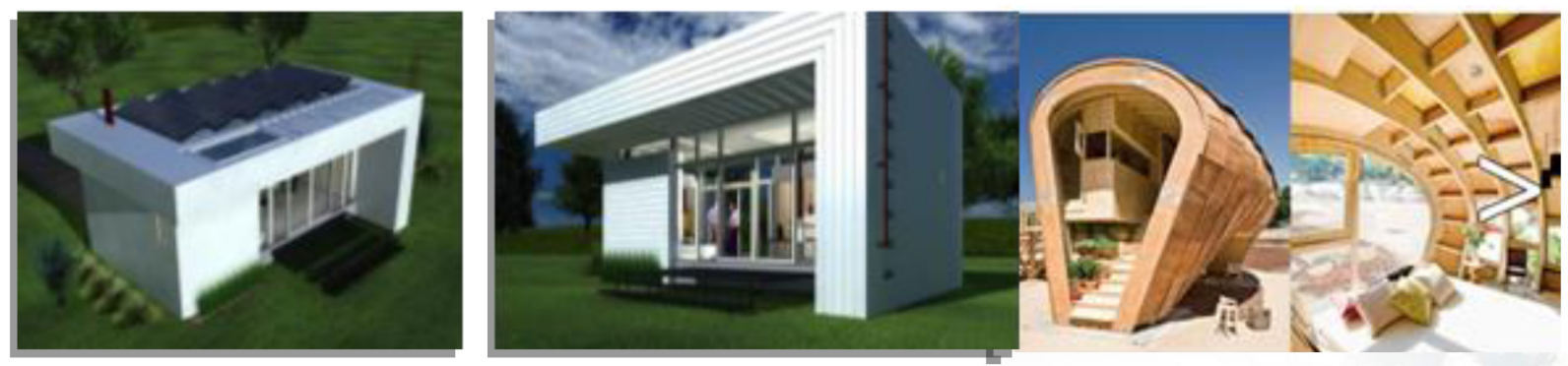

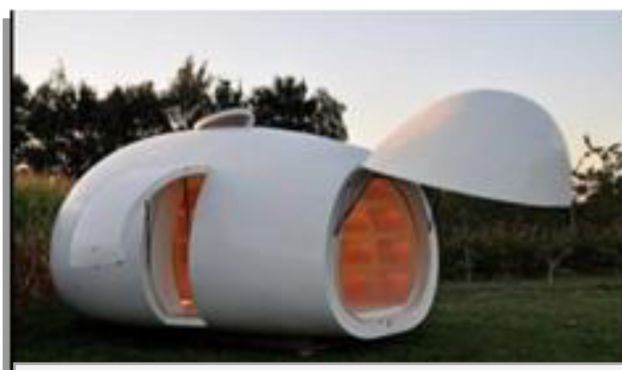

Nano House Design

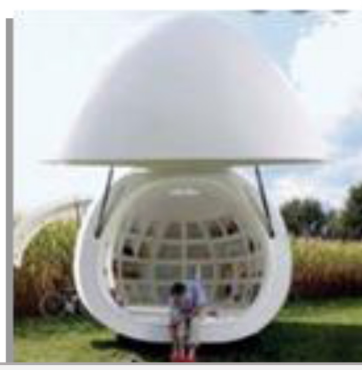

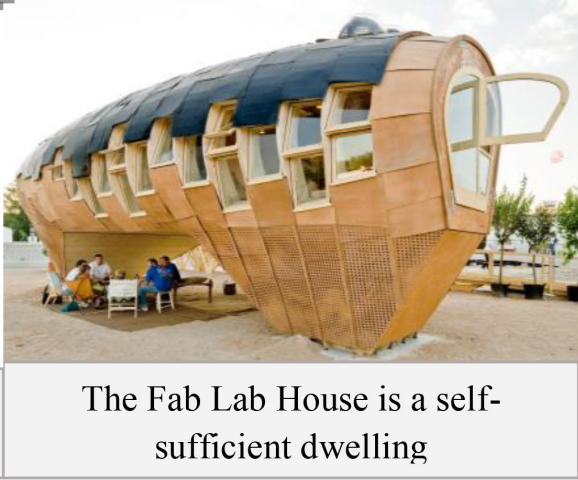

Figure 4. Nano houses as a new type of ultra-energy efficient house. Source:

https://www.pinterest.com/bwandersen5/nano-houses/, and Ossama Omar, Nano architecture Future Housing, Conference: Jourdan Housing Developers Association, At: Amman, April 2015. 


\section{Case Study 2: Torre De Especialidades, Hospital}

\section{Manuel Gea Gonzales:}

Prosolve was chosen by the hospital in part for its anti-microbial, de-polluting effect, as well as providing visual complexity, memorable in form, as a counter to the city's air pollution problem. According to recent studies of the technology, the facade at Torre de Especialidades is reducing the pollution of 1000 cars per day (Figure 5).

\section{Case Study 3: Italian Pavilion, Expo 2010 Shanghai (Better City, Better Life)-Using Nanomaterials and Economic Architecture}

The pavilion presented the Italian people, their creativity and culture using

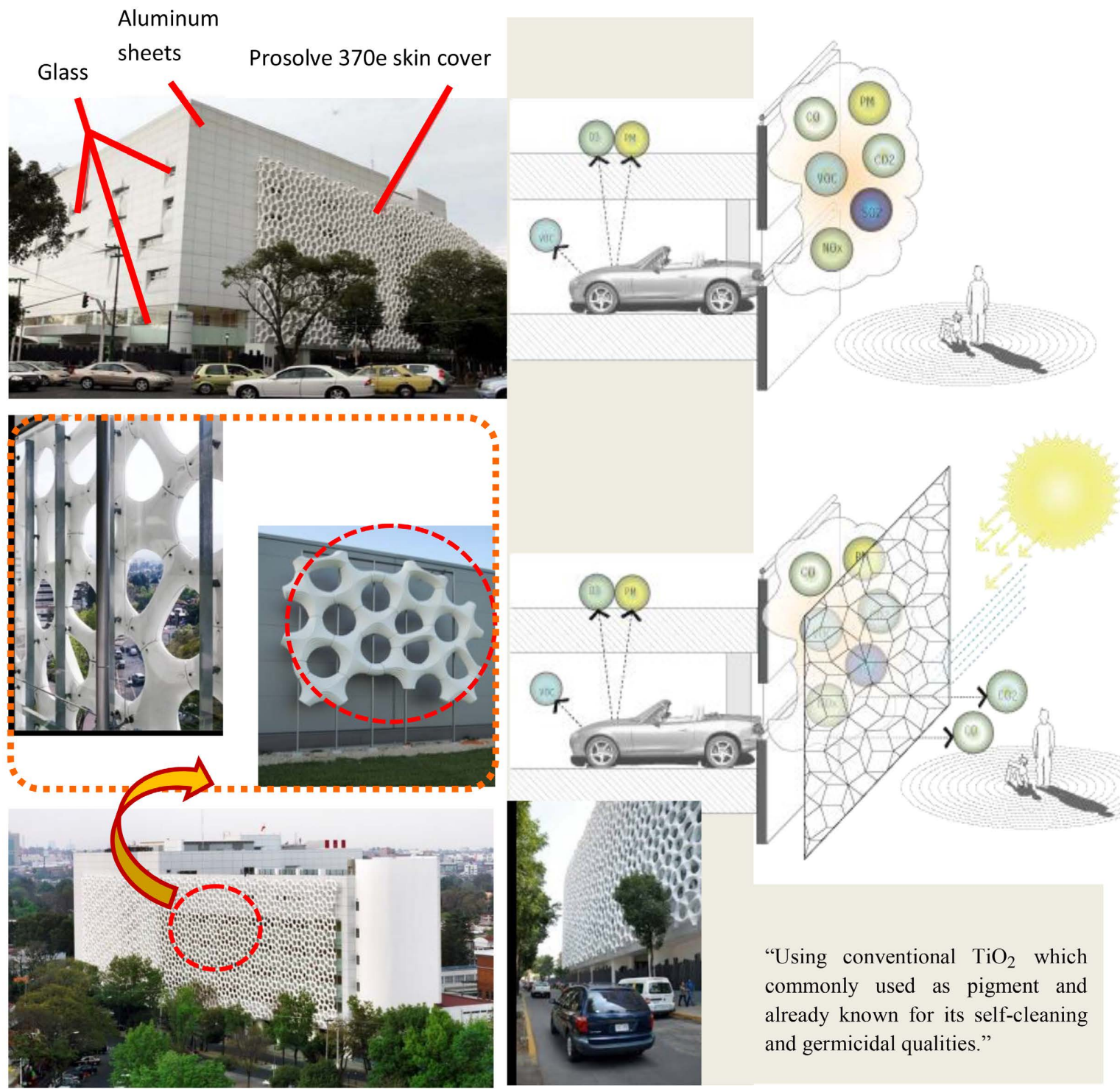

Figure 5. Manuel Gea Gonzalez Hospital using conventional $\mathrm{TiO}_{2}$. Source: Prosolve370e-Elegant Embellishments, Decorative facades that eat pollution "the incredible smog-eating building"-CNN. 
innovative environmentally sustainable construction techniques, [12] technologies and materials, as well as infrastructures. materials used in the pavilion and made out of $40 \%$ recycled materials, and Nanomaterials because Nanomaterial can make constructions more economic because they are ten times lighter but hundred times stronger than regular materials [13] (Figure 6). They focus on energy saving than regular materials.

Using transparent cement (a precast concrete panel) creations involved using fiber optic cables to transmit light, which is an effective method, as shown in Figure 7. Obtained by bonding special resins in an innovative mortar [14], the mixture used has the characteristics and fluidity needed to secure resin in the panels, which allow the optic transmission of light and of the images without compromising the insulative properties and strength typical of a cement-based material. The resins are selected polymers that interacting with artificial as well as natural light, create a warm and soft light inside the building and a picture of light clarity from the outside without creating cracks and compromising the structure.

The project and its specifics find a new method of the building based not only on energy savings, but is representative of a bioclimatic operation. "Inspired by the concept of harmony in variety, Imbroglio Architect's project signifies a look
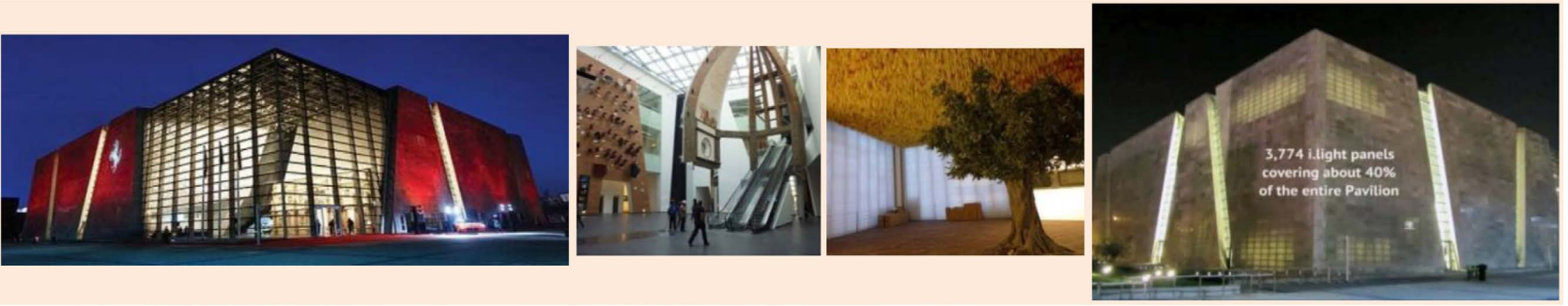

Figure 6. Italian pavilion, Expo 2010 used 40\% recycled materials. Source: Category exhibition, italian pavilion for shanghai Expo 2010.

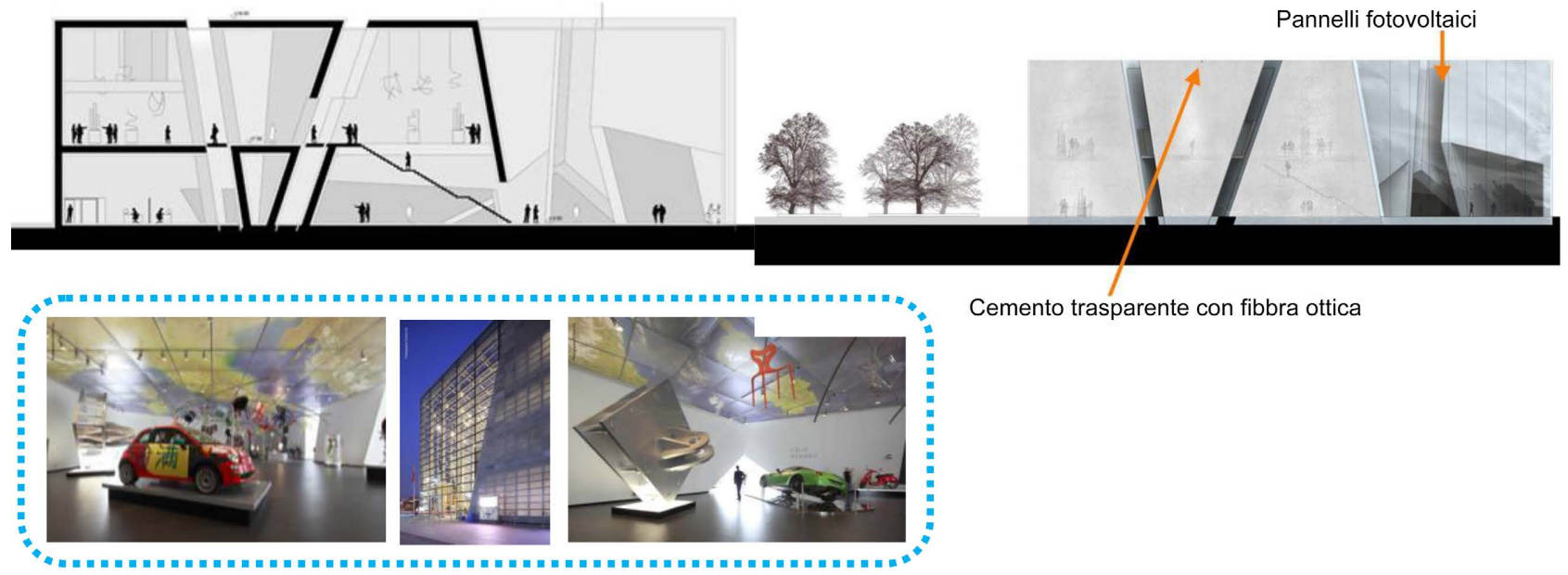

Figure 7. Using transparent cement, to save energy-a bioclimatic operation. Source: Category exhibition, italian pavilion for shanghai Expo 2010. 
into the future through a structure held together by the light. The project was able to carry the image of a country on the move, which intends to be an original and economical player in the globalized world.

The building features a highly flexible interior space in which an artificial landscape made of alleys, streets, and squares is exemplified. The pavilion appears as a city whose crossing is marked by irregular closures and openings suggested by the light, which lights the different areas.

\section{Case Study 4: [Forum Mall, Bengaluru]}

Building Management System (BMS). BMS Provider: Trend Control Systems, Honeywell Forum Mall, Bengaluru, India is fitted with a computerized building management system that senses where the maximum footfalls are leading and increases the cooling and ventilation in those areas (Figure 8). The sensors channel the information to the controllers of the HVAC (Heating, Ventilation, and Air Conditioning, Climate Control) systems, which respond accordingly. Sensors and controllers thus help to optimize the consumption of energy by using networks to relay intelligent inputs detailing the attributes of the physical environment to building services systems.

\section{Case Study 5: Mauritius Commercial Bank Ebene Cybercity Building}

Ebene Cyber City, Mauritius was awarded the Intelligent Building of the year by the Intelligent Community Forum, USA in 2005. It uses an Integrated Management System Comprehensive Integration of all utilities, including HVAC automation, Integration of ventilation and exhaust system to fire and other systems, Monitoring of Vertical transportation System, and Emergency Voice Communication System for Evacuation (Figure 9).

Through the theoretical study, we find that the applications of nanotechnology have been used in different uses of buildings, but not yet used in the buildings of nuclear plants, which would achieve security, safety and environmental protection. Therefore, the research recommends the need to rely on nanotechnology in the construction of nuclear power plants, especially in Dabaa project in Egypt.

\section{Applied Study: Nuclear Plants}

Nuclear is safer than most energy sources and is needed if the world hopes to decrease its carbon emissions [15]. Nuclear power has many advantages, it produces energy, it generates electricity with no output of carbon, switching from coal to nuclear power is radically step to decarbonizing and it releases less radiation into the environment than any other major energy source. Nuclear plants evolved through time and became one of the most important concerns of developed countries. As shown in Figure 10 is historical development of nuclear plants. 

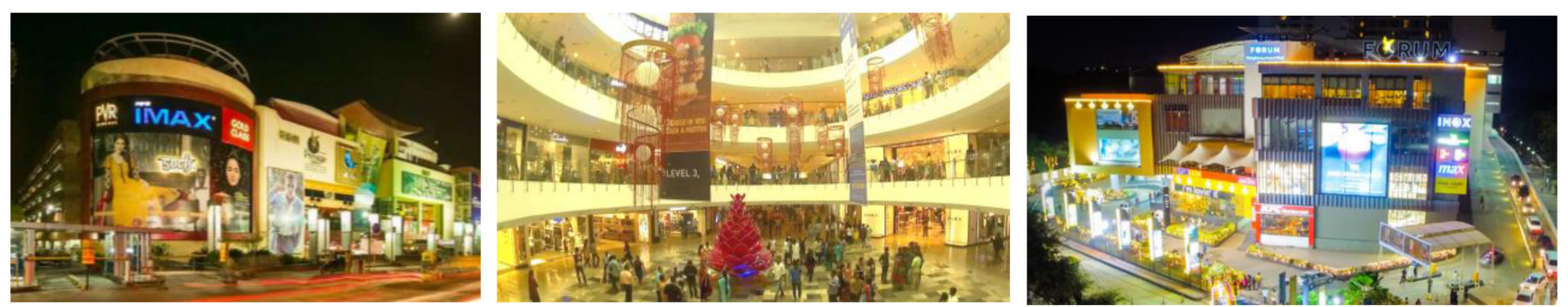

Figure 8. Shows using transparent concrete, HVAC system. Source: Ashish H. Makwana, Darsh Belani, intelligent building new era of todays world, 2014 .

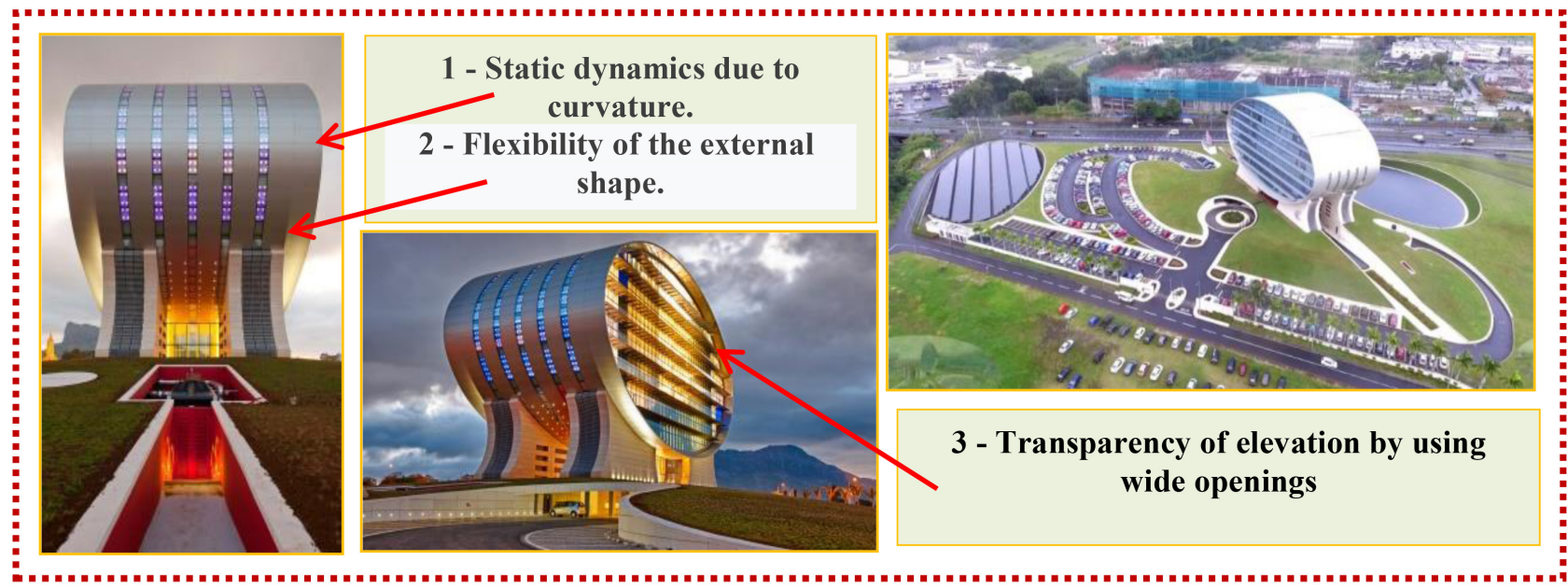

Figure 9. Ebene Cyber City, the intelligent building 2005. Source of pictures: The futuristic building housing the mauritius commercial bank in Ebene Cyber City, Mauritius high-res stock photo-Getty Images.

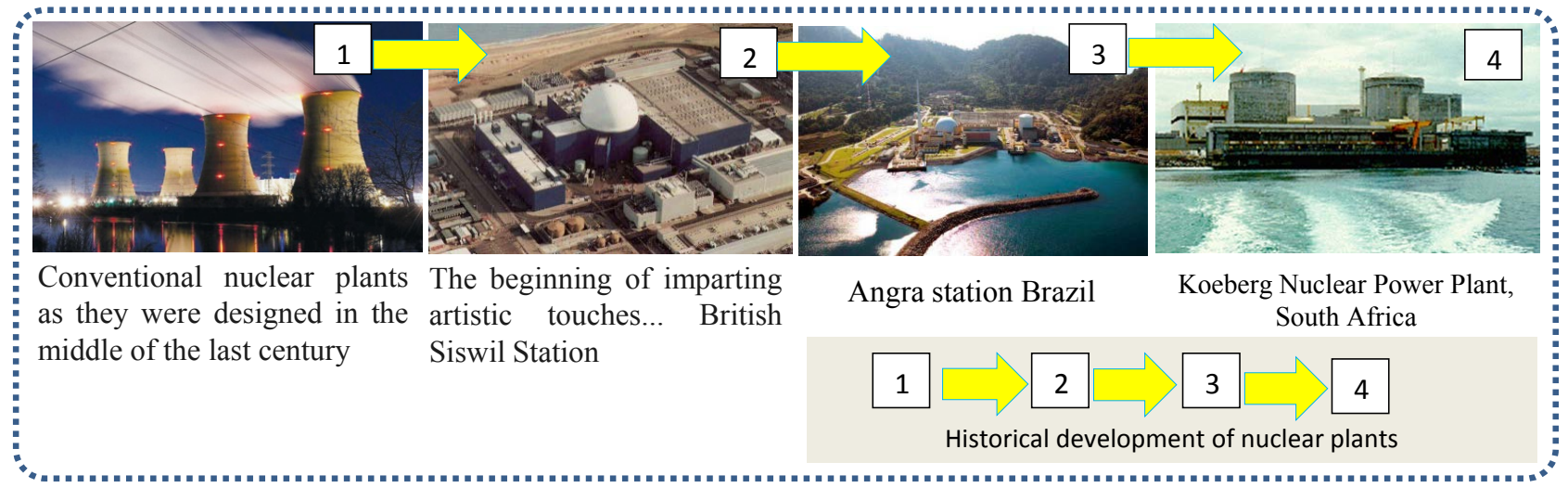

Figure 10. Shows historical development of nuclear plants. Source: Author using nuclear plants pictures Wikipedia.

We find that all of these nuclear plants can be applied nanotechnology in their facilities, whether in the constructional aspects or architectural systems and finishing, which make them more secure and less dangerous to surrounding constructions, especially if such facilities are close to existing urban areas such as Koeberg Nuclear Power Plant, South Africa and Dabaa Nuclear Power Plant, Egypt as shown in Figure 11, Figure 12. 


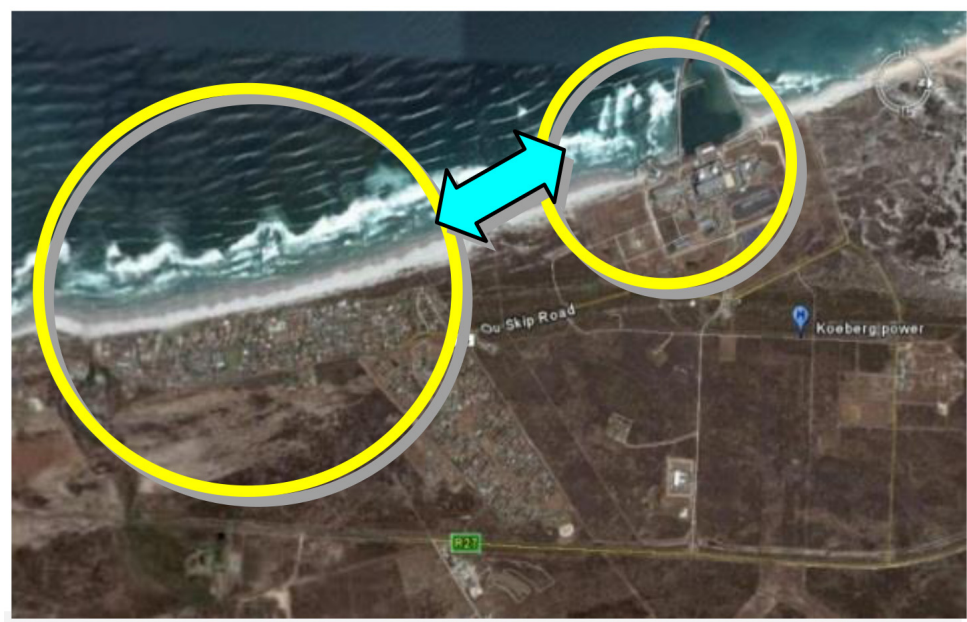

Figure 11. Shows the relationship between Koeberg nuclear power plant buildings and touristic villages viewing the ocean, South Africa. Source: Author.

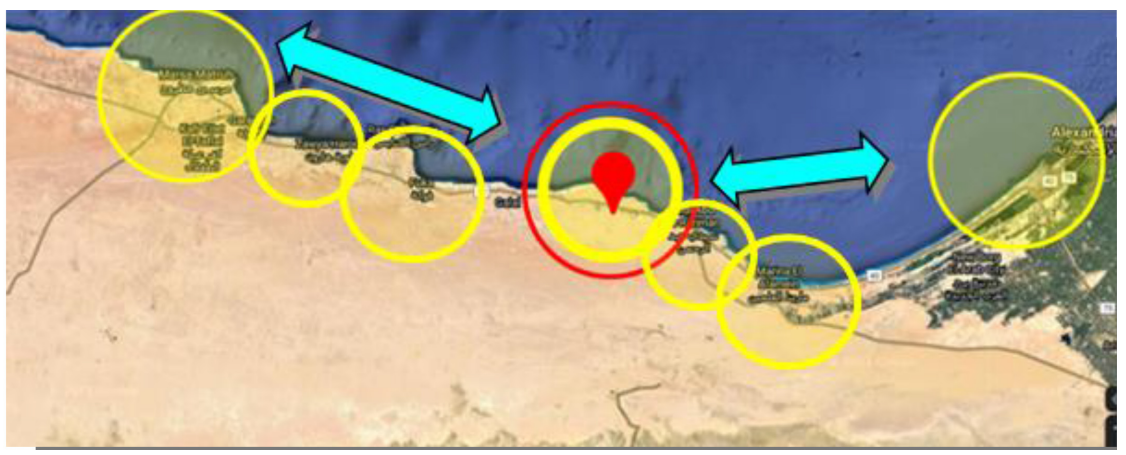

Figure 12. Shows the relationship between EL DABAA nuclear power plant buildings and touristic villages along north coast, Egypt. Source: Author.

\section{Dabaa Nuclear Power Plant, Egypt}

Egypt has come a long way towards achieving the nuclear dream. After many attempts, it is only steps away from establishing its first nuclear plants. The Dabaa nuclear power plant project is one of the major national projects implemented by Egypt, and it represents a major shift for the country in the field of power and electricity generation. The study pointed out that the establishment of advanced nuclear plants put Egypt at the forefront of the developed world, through the economic, technological and social advantages associated with this type of technological application, especially with the tremendous technological advances reached by the nuclear energy sector in the world.

Plant Type: Nuclear power plant (NPP).

Location: Egypt El Dabaa, Matrouh Governorate, $250 \mathrm{~km}$ west of Alexandria (Figure 13).

Capacity: $4.8 \mathrm{GW}$.

There has been a strong realization of the potential threat of both nuclear criticalness and release of radioactive materials. Operation and engineering are designed accordingly. 
One of the most obvious advantages of nuclear power plants is its ability to generate electric power, The net capacity of generating electricity in the Dabaa nuclear power plant is $4800 \mathrm{MW}$, which will increase the volume of electricity generated at the national level, increase Egypt's ability to export energy in the future, and strengthen its strategic position it deserves in the region.

\section{Anotechnology Materials in Construction Process}

According to the previous case studies, the research concluded a group of important applications based on nanotechnology in construction. These applications have to be followed and applied for Dabaa Nuclear Power Plant in a sustainable way through a strategy that achieves the highest level of safety and functional efficiency (Table 1).

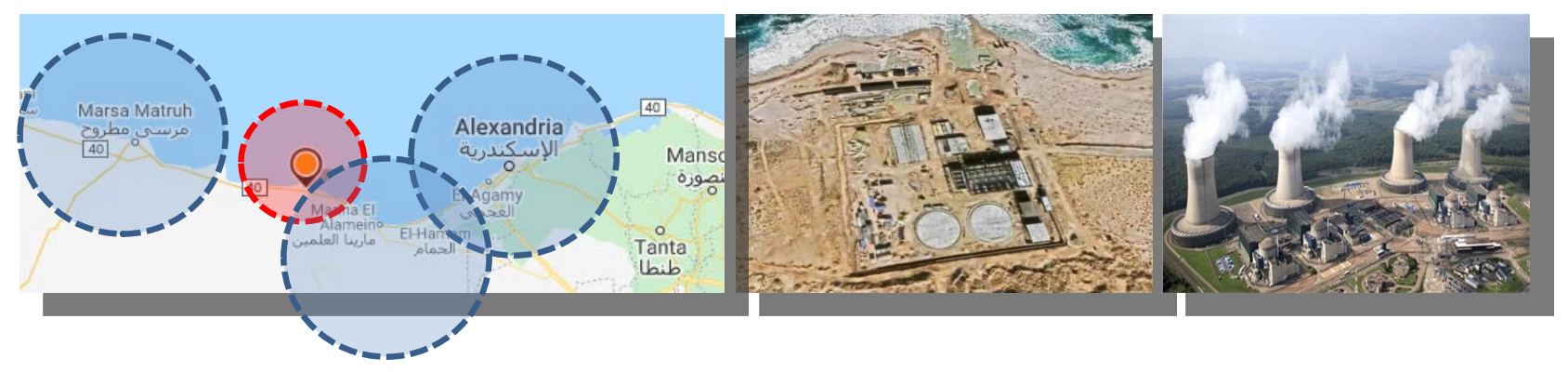

Figure 13. Shows Dabaa nuclear power plant, Egypt. Source: Documents of nuclear plant to be reviewed over 18 months, Egypt Today staff, Nov. 2018.

Table 1. Shows a group of important applications based on nanotechnology in construction. Source: The Author.

\begin{tabular}{|c|c|c|}
\hline Application & Method & Advantage \\
\hline \multirow{4}{*}{$\begin{array}{l}\text { Nanotechnologies for } \\
\text { CONCRETE }\end{array}$} & - Nano-silica $\left(\mathrm{SiO}_{2}\right)$ to cement $[16]$ & Improvements in durability \\
\hline & - Addition 15 of carbon nanotubes & $\begin{array}{l}\text { Improving mechanical properties of mixture } \\
\text { cement \& water }\end{array}$ \\
\hline & - Oxidized multi-walled nanotubes & Improving compressive flexural strength \\
\hline & - Adding Nano scale materials + cement & Improve its performance \\
\hline \multirow{3}{*}{$\begin{array}{l}\text { Nanotechnologies for } \\
\text { STEEL }\end{array}$} & - Incorporate copper nanoparticles & Reducing unevenness then increase safety \\
\hline & - Vanadium \& molybdenum nanoparticles & Reducing $\mathrm{H} 2$ effect then improving the structure \\
\hline & - Adding magnesium \& calcium nanoparticles & Increasing weld toughness \\
\hline $\begin{array}{l}\text { Nanotechnologies for } \\
\text { WOOD }\end{array}$ & - Using Nano fibrils & $\begin{array}{l}\text { Water repellent }+ \text { self-repair }+ \text { self-sterilizing } \\
\text { surfaces }\end{array}$ \\
\hline $\begin{array}{l}\text { Nanotechnologies for } \\
\text { GLASS }\end{array}$ & $\begin{array}{l}-\quad+\mathrm{TiO}_{2} \\
-\quad+\mathrm{SiO}_{2} \text { nanoparticles }\end{array}$ & $\begin{array}{l}\text { - Self-Cleaning } \\
\text { - Fire Protective Glass } \\
\text { - Thermal isolation }\end{array}$ \\
\hline $\begin{array}{l}\text { Nanotechnologies for } \\
\text { PAITINGS }\end{array}$ & $-+\mathrm{TiO}_{2}$ & $\begin{array}{l}\text { - Coat Glazing } \\
\text { - Breaking Down organic dirt } \\
\text { - Thermal control } \\
\text { - Energy sawing }\end{array}$ \\
\hline
\end{tabular}




\section{Proposal for Using Nanotechnology Applications at Dabaa Station}

The research has come up with a strategy, this strategy enables each phase of the material system development to account for critical downstream design constraints constructions, scenarios and efficiencies needed for possible self-sustaining system, state this adaptive material system for the building envelope to optimize material use and to integrate additional functions such as self-sustaining energy production and climate control [17]. In view of the different architectural models of nuclear plants in recent decades, it is clear to us that there are several factors that determine transformations in designs to meet the needs of these plants in accordance with special technology and legislation. It is provided that the main objective is making reactors cleaner, safer and less dangerous (Figure 14).

Proposal for Using Nanotechnology Applications At Dabaa Station:

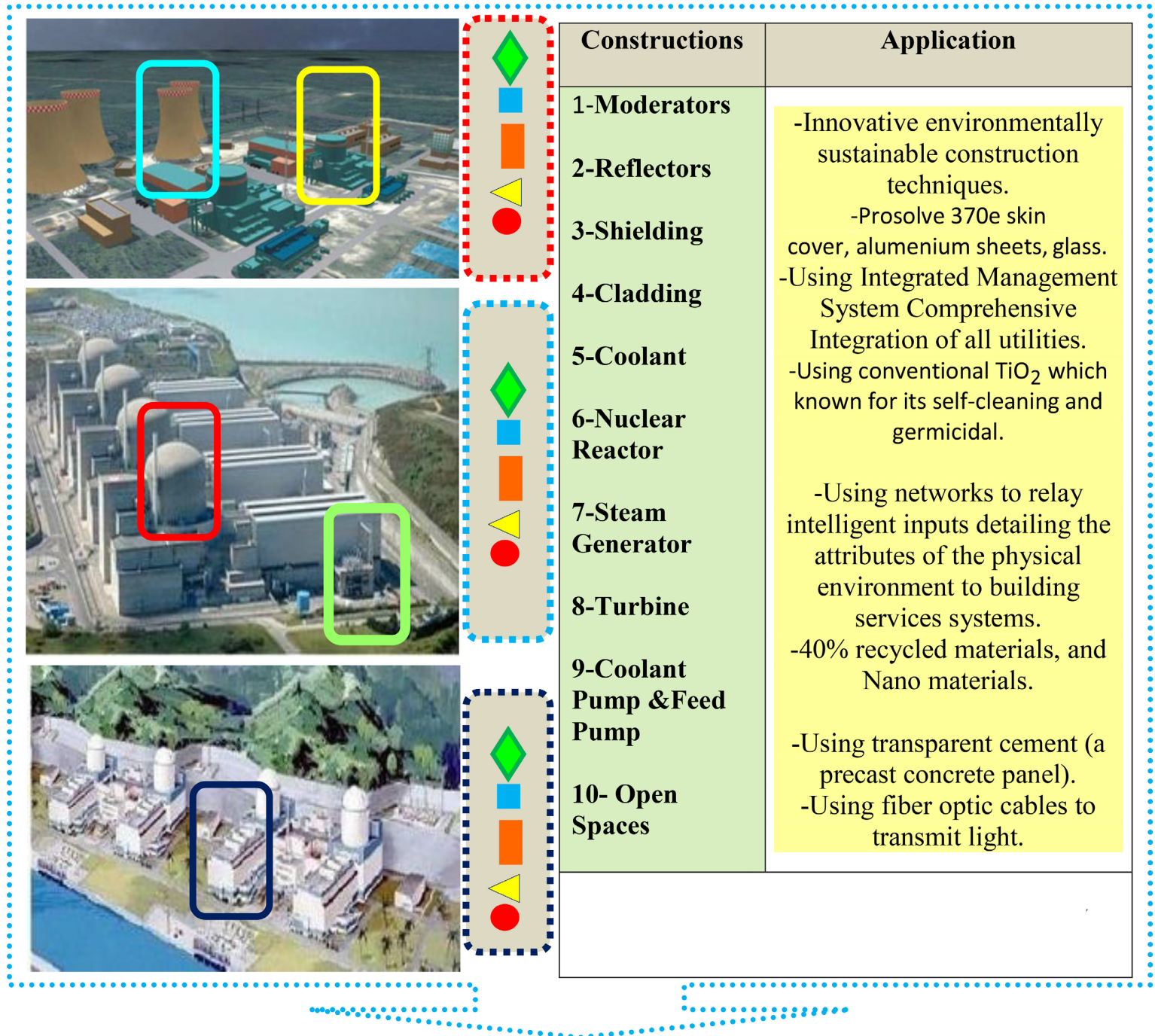

Proposal for Using Nanotechnology Applications at Dabaa Station Source: The Author

Figure 14. Shows a proposal for using nanotechnology applications at Dabaa Station. Source: Author. 
So depending on nanotechnology materials is considered one of the best methods in construction for such this type of buildings to achieve safe and safety and efficiency.

\section{Conclusions}

Nanotechnology construction products have many benefits and avails in the construction process that achieve economic development, The applications of nanotechnology in architecture can vary widely from early stages to the final touches of finishes and throughout the building's lifetime [18]. We need architects, scientists and technologies to give any new regulatory controls are required.

So, the research recommends that it is necessary and urgent to adopt and follow nanotechnology approaches in a sustainable way to save energy, reduce resources consumption and avoid environmental hazards. Therefore, achieve economic development and a sustainable future.

\section{Conflicts of Interest}

The author declares no conflicts of interest regarding the publication of this paper.

\section{References}

[1] Johansen, J. and Princeton, M. (2002) Nano Architecture: A New Species of Architecture. Architectural Press, New York.

[2] Williams, D.E. (2008) Sustainable Design: Ecology, Architecture, and Planning. John Wiley \& Sons, Hoboken.

[3] Fouad, F.F. (2012) Nano Architecture and Sustainability. Department of Architecture Faculty of Engineering, University of Alexandria, Alexandria.

[4] Ashby, M.F., Ferrira, P.J. and Schodek, D.L. (2009) Nanotechnologies and Design: An Introduction for Engineers and Architects. Butterworth-Heinemann, Oxford.

[5] Pelin, Y. (2009) Nanotechnology and Nanomaterials in Architecture. Proceedings of 8 th WSEAS International Conference on Microelectronics, Nano Electronics, Optoelectronics, 30 May-1 June 2009, Istanbul, 120 p.

[6] Pacheco-Torgala, F. and Jalali, S. (2011) Nanotechnology: Advantages and Drawbacks in the Field of Construction and Building Materials. Construction and Building Materials, 25, 582-590. https://doi.org/10.1016/j.conbuildmat.2010.07.009

[7] Nakib, F. (2010) Technological Adaptability: An Approach towards a Flexible and Sustainable Architecture. International Conference on Technology \& Sustainability in the Built Environment, Riyadh, 3-6 January 2010, 479-494.

[8] Gray, A. (2006) How Smart Are Intelligent Buildings? Building Operating Management.

[9] Himanen, M. (2003) The Intelligence of Intelligent Buildings: The Feasibility of the Intelligent Building Concept in Office Buildings. Doctor of Science in Technology Thesis, Helsinki University of Technology, Helsinki.

[10] Simonis, F. and Schilthuizen, S. (2006) Nanotechnology: Innovation Opportunities for Tomorrow's Defence. TNO Science and Industry, The Hague.

[11] Omar, O. (2015) Nanoarchitecture Future Housing. Jordan Project: Zero Energy 
Home. Conference: Jordan Housing Developers Association, Amman, 4 April 2015.

[12] Shebl, S.S., Seddeq, H.S. and Aglan, H.A. (2011) Effect of Micro-Silica Loading on The Mechanical and Acoustic Properties of Cement Pastes. Construction and Building Materials, 25, 3903-3908.

https://doi.org/10.1016/j.conbuildmat.2011.04.021

[13] Gumińska, A. (2017) Correlations between Climate Change and the Modern European Construction. IOP Conference Series: Materials Science and Engineering, 245, 062026. https://doi.org/10.1088/1757-899X/245/6/062026

[14] Yadav, A., Shekhar, S., Anand, A. and Badal, A. (2018, January) An Investigating Study on a New Innovative Material: Transparent Concrete. International Journal of Engineering Research and Advanced Development, 4.

[15] Rhodes, R. (2018) Why Nuclear Power Must Be Part of the Energy Solution. Yale Environment 360.

[16] Ali, A.A. (2020) Nanotechnology in Civil Engineering Construction. International Journal of Structural and Civil Engineering Research, 9.

[17] Mahamed, H. (2010) Nanomaterials and Architecture: "Sustainable Nano Architecture”. Lap Lambert Academic Publishing, Saarbrücken.

[18] Leena, S., Yasin, B. and Atiyat, D.I. (2017) The Effect of Nano Technology on Architecture. International Journal of Advances in Agricultural and Environmental Engineering, 4, 125-129. 